\title{
A questão da Saúde do Trabalhador em empreendimentos autogestionários
}

\author{
Tatiana Dimov e Juliana da Silva Nóbrega ${ }^{2}$ \\ Universidade de São Paulo (São Paulo, SP). \\ Universidade Federal de Rondônia (Ariquemes, RO)
}

Este artigo se propõe a revisitar alguns teóricos da autogestão, da sociologia e da psicologia do trabalho e da saúde do trabalhador a fim de formular uma construção possível de entendimento da saúde do trabalhador dentro do contexto das fábricas recuperadas. Nessas fábricas, os trabalhadores podem participar ativamente das escolhas relacionadas ao processo produtivo e, muito embora o ritmo de trabalho seja pautado pelas empresas capitalistas com quem devem concorrer, podem participar das decisões referentes às condições que regram o ritmo de trabalho. Se problemas relacionados ao adoecimento no trabalho existem, é possível que estes se deem em uma outra proporção em relação ao trabalho na fábrica tradicional. A vantagem do processo autogestionário é a possibilidade de coletivamente se alterar a forma de estar no trabalho com o intuito de buscar o bem-estar coletivo.

Palavras-chave: Autogestão, Saúde do trabalhador, Economia Solidária.

Workers health in self-managing enterprises

In order to understand workers health in factories managed by the workers themselves, this paper brings a review of academics studies about self-management, sociology of work, psychology of work and workers health. In worker-controlled factories, workers can actively participate in choices related to production, and although the pace of work is guided by capitalism, they can make their own decisions regarding the conditions that rules the rhythm of work. However, problems related to occupational illness may exist in different contexts from that of the traditional factory work. The benefit of self-management is the ability to collectively change how to work in order to pursue collective welfare.

Keywords: Self-management, Workers health, Solidary economy.

\section{Introdução}

As mudanças ocorridas no mundo do trabalho nos últimos 30 anos (acréscimo do número de horas trabalhadas, perda de direitos trabalhistas, aceleração no ritmo de trabalho, precarização, mudanças na organização do modo de produção, etc.) são associadas ao aumento significativo da quantidade de trabalhadoras e trabalhadores com LER/DORT (Lesões por esforços repetitivos/ Doenças ósteo-musculares relacionadas ao trabalho). Dejours (2007) relaciona a precarização do trabalho às seguintes consequências: a) intensificação do trabalho e aumento do sofrimento subjetivo dos trabalhadores; b) neutralização da mobilização coletiva, dominação e alienação; c) desenvolvimento, por parte dos trabalhadores, de estratégias defensivas de silêncio, em que não se pode fazer nada pelo sofrimento alheio; e d) individualismo. Todo esse processo está ligado à piora da saúde dos trabalhadores, tanto no que se refere às lesões físicas causadas pelo trabalho quanto à saúde mental destes indivíduos.

De acordo com Sato (1993), o controle sobre o trabalho é um dos principais requisitos para que alguém seja considerado saudável. Há três dimensões a serem analisadas: a familiaridade do trabalhador com o trabalho, que possibilita prever a atividade a ser realizada e seus possíveis problemas; o poder que ele tem sobre o trabalho, que permite que interfira e mude as prescrições e normas da tarefa; e, por fim, o conhecimento dos limites subjetivos, ou dos próprios limites

Bolsista CAPES. Doutoranda no Programa de Psicologia Social da Universidade de São Paulo (PST - IP/USP).

2 Doutora pelo Programa de Psicologia Social da Universidade de São Paulo (PST - IP/USP). Docente do Departamento de Ciências da Educação da Universidade Federal de Rondônia (UNIR), Campus de Ariquemes/RO. 
para a realização de determinada tarefa, podendo variar de acordo com os diferentes contextos. Nas fábricas recuperadas, os trabalhadores podem controlar o próprio ritmo de trabalho e podem participar ativamente das escolhas relacionadas à produção. Neste contexto, embora o ritmo seja pautado pelas empresas líderes de mercado, principalmente as chinesas que superexploram seus trabalhadores e elevam o ritmo a um nível alucinante, os trabalhadores das fábricas recuperadas ainda assim podem participar das decisões referentes às condições que regram o ritmo de trabalho vigente. Sendo assim, talvez não apresentem tantos problemas relacionados ao adoecimento no trabalho. E, se há problemas de saúde vinculados ao trabalho, é possível que estes se deem numa outra proporção em relação ao trabalho na fábrica tradicional. A vantagem do processo autogestionário é a possibilidade de alteração coletiva da forma de estar no trabalho com o intuito de buscar o bem-estar coletivo.

Este artigo se propõe a revisitar alguns teóricos da autogestão, da sociologia do trabalho, da psicologia social do trabalho e da saúde do trabalhador a fim de formular uma construção possível de entendimento da saúde do trabalhador dentro do contexto das fábricas recuperadas. Entendemos que as variadas fábricas recuperadas, com diferentes e diversos processos produtivos, podem apresentar também distinções quanto à questão da saúde em seu interior. Estudos qualitativos, mais específicos sobre a saúde do trabalhador em diferentes contextos autogestionários seriam necessários para o aprofundamento nesta temática. No entanto, na carência de tais estudos, o presente artigo enfoca a autogestão no seu potencial transformador, sem se deter, no entanto, às especificidades dos diferentes segmentos produtivos.

\section{As transformações do mundo do trabalho no Brasil}

A crise do modelo fordista de produção ocorrido nos países centrais, na década de 1970, contribuiu para um processo intenso de reestruturação produtiva no interior da produção capitalista, tendo como implicação processos de flexibilização do trabalho, enxugamento das grandes empresas, eliminação de postos de trabalho, terceirização, trabalhos temporários, etc. Estas mudanças na organização da produção capitalista afetaram intensamente a classe trabalhadora, e, em decorrência deste processo, o desemprego e subemprego atingiram altas taxas em todo o mundo. Afetaram também as organizações sindicais, que viram-se fragilizadas diante do desemprego, tendo como consequência um crescente processo de criação de trabalhos informais (Leite, 2003).

Se os trabalhadores pertencentes aos países que vivenciaram a experiência do Estado de BemEstar Social (Welfare State) foram profundamente afetados, os trabalhadores dos países do Sul, considerados "subdesenvolvidos", como por exemplo, o Brasil, foram ainda mais atingidos. Além de não terem vivenciado a experiência do Welfare State, as condições de trabalho que já eram precárias, mas vistas como provisórias, neste novo cenário tornam-se definitivas, e a possibilidade de inserção em trabalhos formais com direitos sociais deixa de ser uma realidade. Esta situação é constatada por Dedecca (1998), que, ao analisar o mercado de trabalho no Brasil, observa que o mesmo se difere do mercado de trabalho dos países centrais, pois o processo de reestruturação produtiva passa a atingir justamente as categorias de trabalhadores que tinham, por meio da luta e organização sindical, conquistado diversos direitos.

A partir da década de 1990, a situação social dos trabalhadores brasileiros tornou-se mais perversa quando foram implementadas políticas de cunho neoliberal, de incentivo ao Estado Mínimo, redução de recursos para áreas sociais e privatização das empresas estatais, tudo isso tendo como propósito readequar o país às necessidades do capital financeiro. $\mathrm{O}$ processo privatista contribuiu para que milhares de trabalhadores, antes estáveis, fossem demitidos. Por 
outro lado, as empresas estatais passaram a práticas de terceirização e incentivo a planos de demissão voluntária (PDV). De acordo com Esteves (2004), nesse período, o mercado, que até então havia se fortalecido com a organização do vínculo de trabalho assalariado, sofre uma reversão. Esse panorama se modifica e as taxas de desemprego e subemprego crescem consideravelmente no Brasil. Os vínculos empregatícios, baseados na Consolidação das Leis do Trabalho (CLT), são considerados onerosos pelos que contratam e, assim, muitos trabalhadores encontram-se desempregados, ocupados voluntariamente ou trabalhando como autônomos, ou seja, fora desse regime.

Antunes (2005) enumera algumas das mais graves consequências que essas mudanças provocaram ao mundo do trabalho: redução do proletariado fabril estável por conta da reestruturação produtiva; flexibilização e desconcentração do espaço físico produtivo (toyotismo); surgimento de uma grande parcela de trabalhadores em atividades precarizadas (terceirizados, subcontratados, part-time etc); grande exclusão de jovens e idosos do mercado de trabalho; inclusão precoce e "criminosa" de crianças no mesmo mercado nos países em desenvolvimento, mas também em países como a Itália; aumento significativo do trabalho feminino, porém com contratos precarizados e, também, em funções não-intelectuais (destinadas, em geral, aos homens), com média salarial inferior, condições de trabalho e direitos desiguais em relação aos homens; crescimento do trabalho do "Terceiro Setor" em função do desemprego estrutural, entretanto, muito baseado no voluntariado - portanto, incapaz de solucionar o problema; expansão do trabalho em domicílio (e em se tratando das mulheres, mescla-se com o trabalho doméstico); e, por fim, a transnacionalização do capital e do sistema produtivo, o que transnacionalizou o mundo do trabalho.

Apesar das teses que apresentam o processo de acumulação flexível como alternativa ao fordismo e ao taylorismo, responsáveis pela instauração de uma nova forma organizacional das indústrias, da relação capital-trabalho e de um novo trabalhador (mais qualificado e participativo), terem ganhado força nos últimos anos, há ainda muito dissenso com relação a essa concepção. Antunes (2010) ressalta que diversos outros autores apontam que esse "novo" modelo possui continuidades e descontinuidades com os seus antecessores, mas ainda retém o caráter essencialmente capitalista do modo de produção vigente. Para o autor, "as mutações em curso são expressão da reorganização do capital com vistas à retomada do seu patamar de acumulação e ao seu projeto global de dominação" (Antunes, 2010, p. 23).

Como resultado da implementação dessas mudanças, surgiu uma classe trabalhadora heterogênea, fragmentada e complexificada. Ao contrário dos que defendem que o trabalho perdeu sua centralidade, a classe-que-vive-do-trabalho continua existindo e tem como desafio firmar os laços de pertencimento dos diferentes segmentos que compreendem o mundo do trabalho. Atualmente, mesmo estando em outro momento político do país, a maior parte da força de trabalho encontra-se nos países "em desenvolvimento" em situação precária. As taxas de desemprego e subemprego permanecem altas, pois trata-se de um problema social complexo e, diante do atual contexto histórico, social e político, difícil de se resolver. $\mathrm{O}$ "fim do trabalho" é uma tese que não se aplica a esses países. Emprego, estabilidade, aposentadoria, direitos trabalhistas, entre outros, fazem, cada vez mais, parte do passado. A mobilidade do mercado de trabalho favorece, cada vez mais, relações de trabalho precárias que terminam por influenciar as condições de trabalho e saúde daqueles que ainda estão empregados (Lancman, 2004).

Este breve relato acerca das transformações ocorridas no mundo do trabalho demonstra que as mesmas têm contribuído para mudanças importantes, a saber: o crescente processo de precarização do trabalho, o aumento do trabalho informal e a crescente inserção das mulheres no mercado informal de trabalho. 


\section{O campo da Saúde do Trabalhador}

Castel (1998) aponta o trabalho como matriz da integração social e constituinte da identidade do sujeito, estabelecendo uma relação causal entre as diferentes formas de inserção no trabalho e a vulnerabilidade dos grupos em relação a sua inserção social. Lancman (2004) entende que o trabalho nunca é neutro, e é, além de fonte de renda, oportunidade central de crescimento e desenvolvimento psíquico. Sendo assim, há uma contradição entre a racionalidade das empresas, focadas no lucro e na produtividade (transformando os trabalhadores em peças a serem calibradas) e a própria saúde mental dos trabalhadores, permeada pela lógica interna destes sujeitos, por suas angústias, medos, ansiedades, etc. A autora acredita que as ações de prevenção em saúde do trabalhador devem se dar a partir de mudanças concretas na organização do processo produtivo, que precisam permitir ao trabalhador não apenas uma tomada de consciência, mas também uma instrumentalização que possibilite mudar sua relação com o trabalho.

Ainda na década de 1970, as transformações socioeconômicas vividas na maioria dos países da América Latina chamaram a atenção para a relação entre estas e a saúde-doença, passando a ser o objeto de estudo da Saúde Coletiva, amplamente influenciada pela Epidemiologia. Os estudiosos desse campo passaram a buscar a determinação social dos agravos à saúde do trabalhador, situando ali o papel central do trabalho. De acordo com Sato et al. (2006), tratava-se do resgate do ethos de um trabalho emancipador e também de superar a epistemologia vigente da Medicina do Trabalho, apreendendo a íntima relação entre o processo de organização/divisão do trabalho e suas implicações para os trabalhadores, não mais se restringindo a sua constituição ambiental (fatores e agentes de risco externos ao trabalhador). Em decorrência dessa nova perspectiva, a Saúde Coletiva incorpora também a visão do trabalhador como "sujeito de mudanças, com saberes e vivências sobre seu próprio trabalho, compartilhadas coletivamente" (Sato et al., 2006, p. 283). Esses postulados permitem a construção de políticas públicas de saúde de cunho político, voltadas a um maior compartilhamento de conhecimentos sobre a relação entre saúde e trabalho entre os próprios trabalhadores. O campo da Saúde do Trabalhador surge no Brasil em decorrência desses debates, e com o fim da ditadura militar e a redemocratização da sociedade, a Saúde aparece como direito social pela primeira vez na constituição brasileira, a partir da criação do Sistema Único de Saúde (SUS), também responsável por implementar ações voltadas à saúde dos trabalhadores.

Se, por um lado, a luta pela saúde enquanto direito dos trabalhadores apresenta todas essas conquistas, por outro, a precariedade das condições de saúde e de segurança de muitos trabalhadores ainda é um desafio a ser superado. De acordo com o relatório da Organização Internacional do Trabalho (OIT) sobre ambientes de trabalho seguros e saudáveis (OIT, 2007), 2,2 milhões de pessoas morrem por ano no mundo por acidentes de trabalho ou doenças laborais. No Brasil, a situação é alarmante. Segundo dados do Anuário Estatístico da Previdência Social (AEPS), ocorreram apenas em 2012 cerca de 705.239 casos de acidentes ou adoecimentos. Os números não são tão discrepantes em relação aos anos anteriores. Dentre esses, 163.953 casos foram registrados entre trabalhadores sem carteira assinada, categoria na qual, possivelmente, encontram-se alguns trabalhadores de cooperativas.

Apesar das conquistas das lutas populares, do chamado "avanço" da ciência e da tecnologia no nosso século, o bem-estar dos trabalhadores da "base" produtiva e, portanto, mais pobres, ainda é bastante insuficiente. Há muitas lacunas na distribuição destas conquistas, dependendo sensivelmente dos setores de interesse do grande capital, atualmente legitimado pelo Estado.

As condições de saúde e de segurança no trabalho espelha a desigualdade social presente na sociedade capitalista. Nesta, a importância da saúde e da dignidade humana deixa de ser um ideal, passando a ser determinada perversamente pela lógica do capital, em que o lucro tem mais valor do que a vida humana. Em tais condições, o ser humano é regulado e moldado pelas necessidades 
de mercado e submete-se à exploração sem se importar, já que é através deste ato que garante sua sobrevivência. Nesta relação de exploração de sua própria força de trabalho, acaba relegando sua saúde para o segundo plano. Mesmo com o rigoroso "avanço tecnológico", a exploração da força de trabalho continua sendo grande fonte "geradora de renda", tanto para os grandes capitalistas, quanto para os trabalhadores autônomos que se submetem à relação de trabalho informais. Estes últimos frequentemente desconhecem seus direitos sociais e não percebem o nexo entre o trabalho e a saúde, adoecendo e deixando de lutar por condições de trabalho adequadas.

\section{O debate da Economia Solidária}

De acordo com Milton Santos, imprimimos no espaço transformações que alteram nossas relações sociais e vice-versa, sendo esse um movimento incessante. A cada dia, novas técnicas e novas relações são criadas. A racionalidade tecnocientífica se impõe a todos, transformando os espaços com o objetivo de controlar seu desenvolvimento. Santos (2010) acredita que essa racionalidade que parece abarcar a todos é incapaz de impedir totalmente o aparecimento das contradições explícitas no cotidiano das pessoas. A ausência de políticas públicas efetivas de seguridade social e de garantias mínimas de sobrevivência exige buscas ativas de soluções que caminham em uma direção oposta à da racionalidade tecnocientífica. Desencadeiam, então, processos de resistência que procuram estabelecer outra racionalidade, mas que, ao mesmo tempo, coexistem nesta sociedade.

Em meio a essas transformações enunciadas anteriormente, inúmeras experiências de trabalho associado e autogestionário despontaram no fim da década de 1990. Segundo Leite (2003), apesar das políticas de governo adotadas no país e das formas de inserção da economia brasileira na globalização serem de caráter extremamente excludentes, ainda assim, nem tudo que acontece no país se define por isso: “(...) pelo contrário, reagindo às consequências nocivas desse processo, a sociedade vem se movimentando em direção a modos alternativos de produção, criando novas formas de subsistência, novas institucionalidades e novas formas de governance” (p. 19). No início do século XXI, gestões públicas, tanto progressistas quanto conservadoras, começaram a assumir a Economia Solidária como política de governo e, mais raramente, como política pública. Na mesma linha, setores da sociedade civil e organizações sociais, como grupos de jovens católicos, a Cáritas Internacional, movimentos sociais e universidades, optaram e viram na Economia Solidária a possibilidade tanto de gerar renda quanto de promover uma sociedade mais justa e igualitária.

Alguns trabalhadores começaram a buscar outras maneiras de garantir sua sustentabilidade. Uma das formas encontradas para isso foi a organização coletiva de trabalhadores em cooperativas ou associações de trabalho, serviços ou produção e a recuperação de empresas falidas, todas elas de caráter organizativo autogestionário. Como argumentou León-Cedeño (1999), há diversos sentidos para a autogestão, cujas diferenças são sutis e dão lugar a mundos completamente diferentes. Bernardo (2005) sugere que pensemos nos processos autogestionários como tendências a uma sociedade transformada. Ele diz:

Assim, na fase actual o importante é desencadear o começo de uma tendência. $\mathrm{O}$ máximo a que podemos aspirar para já é o desenvolvimento de lutas que tendam à autonomia, em que a participação de todos tenda a ser cada vez maior, em que a rotatividade nas funções tenda a ser crescente, em que o leque das remunerações - se for caso para existirem - tenda a reduzir-se. Este 'tenda a' não se consegue sem luta. Trata-se de uma luta dentro da luta, e só o processo permanente de luta interna pode garantir que as experiências de libertação não se convertam, como até agora tem sucedido, em novas experiências de opressão (p. 2). 
Dessa forma, falamos aqui de grupos de trabalhadores que optam por construir coletivamente um empreendimento, do qual tirarão o sustento necessário para sua vida a partir da tentativa de fazer parte dessa tendência. São variados os formatos dessas experiências (como cooperativas e associações), que podem ter sido criadas para isso ou serem frutos de processos de recuperação de empresas falidas.

Para se configurarem como empreendimento de Economia Solidária, estes grupos tomam a autogestão como modelo organizativo (Singer, 2002). A Economia Solidária, compreendida em um sentido mais amplo como um modo de produção autogestionário e cooperativo, não é recente na nossa história. Enquanto projeto de sociedade, surge no Brasil, no fim do século XIX, durante a vinda de imigrantes para o país, que traziam consigo a noção de cooperativismo. Depois de passar por um período de latência e de acúmulo de experiências, novamente, no fim da década de 1980, a Economia Solidária ressurge com novos formatos, redesenhada, despontando esperanças entre os que vivem a crise do emprego. A partir daí, foram criadas muitas cooperativas, associações, Oscips, entre outras, e construi-se a Secretaria Nacional de Economia Solidária (SENAES) ligada ao Ministério do Trabalho. O próprio Movimento dos Trabalhadores Sem Terra (MST) aposta no cooperativismo como forma coletiva de produção, criando, em 1992, a Confederação das Cooperativas de Reforma Agrária do Brasil (CONCRAB) e desenvolvendo, ao longo do tempo, uma noção de cooperação que permite combinar interesses individuais com os coletivos, conforme aponta Scopinho (2007).

Autogestão, no entanto, não é garantia de bem-estar dos trabalhadores. Lima (2007) e Georges (2009) trazem análises de que o trabalho de empreendimentos entendidos como autogestionários são usados pelo capital como estratégia para diminuição de custos da força de trabalho, uma vez que os trabalhadores autogeridos não contam com as mesmas garantias trabalhistas dos trabalhadores contratados.

No entanto, coletivos de trabalhadores seguem apostando na organização autogestionária como estratégia de empoderamento. O Movimento Nacional de Catadores de Materiais Recicláveis (MNCR, 2009) coloca:

A luta pela autogestão do trabalho e o avanço no controle da cadeia produtiva de reciclagem são estratégias fundamentais para garantir que o serviço realizado pelos catadores e catadoras não seja utilizado em benefício de alguns poucos exploradores deste tipo de trabalho, mas que sirva ao fortalecimento econômico da categoria de catadores (p.13).

Faria (2009), distingue a autogestão em duas formas: autogestão social e autogestão na unidade de produção. Neste trabalho, entendemos a autogestão na unidade de produção como sinônimo de Economia Solidária, utilizando a definição assumida por Cruz (2006), na qual a Economia Solidária é:

Conjunto das iniciativas econômicas associativas nas quais (a) o trabalho, (b) a propriedade de seus meios de operação (de produção, de consumo, de crédito etc), (c) os resultados econômicos do empreendimento, (d) os conhecimentos acerca de seu funcionamento e (e) o poder de decisão sobre as questões a ele referentes são compartilhados por todos aqueles que dele participam diretamente, buscando-se relações de igualdade e solidariedade entre seus partícipes (p.69).

Para Quijano (2005), o que diferencia a Economia Solidária de uma economia capitalista é a autogestão, traduzida por um posicionamento político e ideológico que busca a transformação do sistema em todas as suas dimensões. Boaventura de Souza Santos (2002) salienta que tanto a Economia Solidária como outros movimentos sociais contemporâneos são experiências que se 
caracterizam pela busca de sociabilidades e práticas anticapitalistas, que ao criticarem e buscarem a superação das características desse sistema, "têm em comum o fato de, ainda que não pretendam substituir o capitalismo de um só golpe, procurarem (com resultados díspares) tornar mais incômoda sua reprodução e hegemonia." (Santos, 2002, p. 29). Nesse sentido, as práticas de associativismo e cooperativismo pela autogestão poderiam ser caracterizadas como contra-hegemônicas, pois vão na corrente contrária do modelo econômico, político e cultural dominante.

A partir do momento em que os trabalhadores se organizam dessa maneira, uma nova experiência de trabalho começa a ser vivenciada pelos mesmos. Nova porque trabalhar de forma associada difere de trabalhar para um patrão. $O$ controle do processo organizativo é do coletivo de trabalhadores e não mais da gerência de uma ou duas pessoas, e isso permite que escolhas organizacionais sejam tomadas por todos. Assim, a forma como se dá a produção, as máquinas escolhidas para trabalhar e o jeito como serão utilizadas, o ritmo de trabalho, os horários para descanso, para alimentação e outros momentos, tudo isso é definido coletivamente, dentro do possível.

Por outro lado, as cooperativas de produção inseridas no sistema capitalista estão também submetidas à lógica do mercado, sendo obrigadas a intensificar seu ritmo produtivo para que sejam competitivas. Os trabalhadores destas cooperativas veem-se, então, na situação de "governar a si mesmos com todo o absolutismo necessário" (Luxemburgo, 2003), passando a atuar, de forma coletiva, como os próprios patrões capitalistas.

Evidencia-se aqui, portanto, a lógica da autoexploração, em que, por um lado o trabalhador vê-se obrigado a manter um ritmo alucinante e insalubre de produção mas, por outro, tem maior autonomia nas decisões relativas ao processo produtivo. Retomando Dejours (2007), podemos inferir que, devido ao sistema de organização autogestionário, os trabalhadores de EESs, por mais que se vejam obrigados a intensificar o ritmo de trabalho, ainda resistem contra a alienação e a dominação, sendo capazes de mobilizarem-se coletivamente, o que neutraliza as estratégias defensivas de silêncio e o individualismo. Deste modo, de acordo com os critérios estabelecidos pelo autor, entendemos que os trabalhadores de EESs ainda não atingiram uma situação ideal de trabalho, mas já avançaram alguns passos em relação aos trabalhadores de empresas capitalistas convencionais.

\section{Economia Solidária e o olhar para a Saúde do Trabalhador}

A produção teórica na área da saúde em interface com a Economia Solidária tem se debruçado sobre a questão do cooperativismo como alternativa de inclusão no trabalho para as populações com necessidades especiais, focando principalmente nas experiências das chamadas cooperativas sociais (Carreta, 2005; Nicácio, Mangia \& Ghirardi, 2005; Ghirardi, 2004; Lancilotti, 2003; Barros, Lopes \& Ghirardi, 2000) e, mais recentemente, em iniciativas envolvendo usuários de serviços de saúde mental (Andrade, Burali, Vida, Fransozio \& Santos 2013; Filizola, Teixeira, Milioni \& Pavarini, 2011; Barfknecht, Merlo \& Nardi, 2006). Do ponto de vista da saúde e da segurança no trabalho, são escassas as pesquisas existentes em cooperativas e, mais ainda, em fábricas recuperadas.

Dos estudos que focalizaram o cotidiano das cooperativas e a forma como os trabalhadores falam sobre a saúde, dois se destacaram. Lima e Gomez (2008), estudando cooperativas de construtores de casa, colocam que, neste caso, a experiência associativa permite uma inserção social mais justa e equalitária, configurando-se, portanto, como uma prática produtora de saúde. Sícoli (2007), que estudou a saúde dos trabalhadores de uma cooperativa de triagem em Embu, no estado de São Paulo, coloca que, embora a organização associativa possa ter características de 
potencialização da saúde do trabalhador, na medida em que permite a autonomia do processo de gestão do trabalho, por outro lado, a própria cooperativa também sofre as pressões produtivas do mundo capitalista quando se relaciona com o mercado externo a ela o que gera um processo de autoexploração, pelos próprios cooperados, na tentativa de assumir as demandas do mercado.

Já do ponto de vista do fomento dessa discussão dentro das cooperativas pelas instituições apoiadoras, chamou atenção também a pesquisa de Azevedo e Sousa (2013), que estudaram a temática da saúde do trabalhador em fábricas recuperadas e encontraram que, embora a saúde do trabalhador seja considerada importante, o trabalho das CIPAs (Comissão Interna de Prevenção de Acidentes) nessas fábricas ainda é incipiente. Neste texto, as autoras salientam a importância e o limite da contribuição das instituições de apoio às cooperativas no que concerne essa temática. Ao entrevistarem os dirigentes da OCB e da UNISOL, constataram que uma vez que as cooperativas têm autonomia em suas decisões, o alcance dessas instituições torna-se menor, podendo apenas informar e colaborar com a discussão. $\mathrm{O}$ artigo limita-se a essas duas instituições, não alcançando porém as percepções das outras agências de fomento à economia solidária, como as Incubadoras Tecnológicas de Cooperativas Populares (ITCPs) ligadas à Rede de Incubadoras, à Unitrabalho, à Associação Nacional de Trabalhadores e Empresas de Autogestão (ANTEAG), entre outras. É possível que nessas diferentes instituições apareçam diferentes formas de abordar a saúde do trabalhador em cooperativas, porém, em nossa revisão bibliográfica não encontramos publicações a este respeito (foram consultadas as bases de dados Scielo e os periódicos da CAPES).

A Saúde do Trabalhador dentro do contexto da Economia Solidária aparece, então, como um campo que carece ainda de embasamento teórico, necessitando de mais estudos que aprofundem esta questão em diferentes contextos produtivos autogeridos. São poucos e recentes os estudos sobre a saúde do trabalhador em empreendimentos autogeridos. Não existem ainda pesquisas que indiquem os tipos de doenças relacionadas ao trabalho que acometem os trabalhadores autogestionários, ou quais as estratégias de prevenção de doenças relacionadas ao trabalho adotadas nos diversos empreendimentos autogeridos. São necessários mais estudos nesta área, que avaliem a questão da saúde do trabalhador em diferentes contextos de produção autogestionária, uma vez que os diferentes tipos de organização associativa e os diferentes processos produtivos podem acarretar em diferentes impactos para a saúde dos trabalhadores envolvidos.

\section{O cotidiano, o controle dos trabalhadores e a saúde nos processos organizativos autogestionários}

Quando se pensa na palavra "organização" no contexto do trabalho, logo vêm à mente todos aqueles processos que são de responsabilidade da gerência em uma fábrica heterogestionária (Spink, 1996). Porém, do ponto de vista sociotécnico, organização é muito mais do que isso. Trata-se de uma produção intersubjetiva de sentidos que circula no cotidiano do trabalho. Ainda que pareça obra de um grupo distinto que planeja o cotidiano de terceiros (gerentes, coordenadores, supervisores), a organização é um produto social que envolve a todos e não um fenômeno independente dos processos cotidianos de negociação entre os trabalhadores. Mesmo que uma ordem venha de "cima para baixo", ao chegar no "chão da fábrica" será redesenhada pelos trabalhadores.

No tocante à saúde do trabalhador, isso foi apontado nos estudos da Psicologia Social do Trabalho, mais especificamente nas pesquisas feitas por Sato (2002) sobre a resistência à ideologia gerencial para prevenção de acidentes no chão de fábricas. Neste artigo, a autora busca refletir sobre a existência de outras racionalidades para a organização do trabalho além daquela vinda da gerência. Segundo Sato (2002), apesar da concepção da organização do trabalho ser feita pela gerência de forma unilateral: 
No chão de fábrica, as pessoas, através do conhecimento construído na prática, o replanejam para então executá-lo, tanto com a finalidade precípua de amenizar os esforços do trabalho, como para manifestar a resistência política ao poder e controle gerenciais ou ainda, para tornar factível aquilo que foi planejado por outrem (p. 1148).

Isso, atrelado às pesquisas feitas nos locais de trabalho, corrobora a ideia de que a questão da prevenção aos agravos na saúde do trabalhador é uma questão que envolve a participação e o controle dos trabalhadores no processo de trabalho e também que o cotidiano dos trabalhadores está repleto de conhecimentos e formas ou estratégias a respeito do que se deve ou não fazer no trabalho para que o adoecimento seja evitado.

Em uma empresa heterogestionária isso se dá de forma limitada, dentro das negociações internas que são possíveis na dinâmica existente. Limitado para quem está de fora, observando criticamente e esperando por uma transformação radical no processo de trabalho. Entretanto, segundo Sato (2002), para os trabalhadores, as micronegociações cotidianas sobre o modo de trabalhar têm um efeito transformador, uma vez que, além de se preservarem, também se colocam como sujeitos ativos no processo de trabalho e não como meros cumpridores daquilo que vem de cima.

O conhecimento/subjetividade operária e as micronegociações são fenômenos da mesma ordem: os trabalhadores são construtores de conhecimento, articulam-se de modo conflituoso e cooperativo, e criam modos de vida singulares nos locais de trabalho (Sato, 2002, p. 1165).

Portanto, a organização é um processo que envolve negociações de interesses distintos e que trabalhadores continuam sendo pessoas com seus valores, crenças e conhecimentos, a despeito do corpo gerencial e do capital lhes tratarem como "recursos humanos", e dos processos de trabalho serem organizados para estes "recursos" e não para pessoas. Por esse motivo, tanto Spink (1996) quanto Sato (2002) adotam o termo "processos organizativos de trabalho" em vez de "organização". Para Sato (2002), em qualquer organização na qual o poder venha não dos trabalhadores, que constroem diariamente o trabalho, mas de um grupo de pessoas proprietárias privadas ou de algum grupo da legalidade, está montado o palco para que as pessoas sejam unidas às máquinas e equipamentos, como mais um entre os recursos daquele lugar (o que não significa que não haverá resistências por parte dos mesmos). A CLT é a instituição social desta visão, pois permite que o empregador tanto empregue quanto demita alguém conforme sua necessidade, além do poder de mando e controle do trabalho do mesmo, obviamente dentro dos limites contratuais, mas sempre no sentido de uni-lo como peça junto aos outros recursos físicos da empresa.

Entretanto, quando esses trabalhadores resolvem constituir-se sob formas organizativas autogestionária e tornam-se sócios-trabalhadores, começam a construir um novo processo organizativo, que envolverá outros tipos de problemas a serem debatidos, não mais da ordem da subordinação. Agora não podem mais ser mandados, substituídos, contratados ou demitidos. Precisam dar conta de gerenciar coletivamente o processo produtivo que lhes cabe. No dia a dia desse fazer coletivo vai sendo evidenciado que um empreendimento não se faz sozinho, não é dado, não é natural, e sim sociotecnicamente construído. Precisam lidar com as contas, as vendas, as retiradas, a divulgação, o controle da produção, etc. Essa realidade provocará um processo de construção de novos conhecimentos e novas qualificações. Esse processo é difícil de ser vivido e, muitas vezes, a necessidade de garantir o governo cotidiano de todos os trabalhadores é deixada de lado ou é vista como algo que atrapalha a eficiência do trabalho.

A solução possível para esse impasse parece se - caso se mantenha em termos democráticos - a permanente negociação dos interesses e das possibilidades, coletivos e individuais, dos sóciostrabalhadores, visando tomadas de decisão coletivas que, por meio de um percurso de escolhas organizacionais, definam o funcionamento do grupo. Quando tal processo ocorre, revela aos 
envolvidos sua capacidade política (que está sempre presente) para a gestão do empreendimento (Esteves e Sato, 2002, p. 13).

Além daquilo que habitualmente é visto como instância de decisão coletiva - as assembleias, por exemplo - há muitas outras situações em que os trabalhadores decidem e fazem escolhas organizacionais. São momentos que passam despercebidos, mas que envolvem questões importantes para o processo organizativo. Segundo Sato \& Esteves (2002), a assembleia é apenas a "ponta do iceberg" desse processo, mas há outros.

No dia-a-dia - naqueles momentos que não são considerados memoráveis - também se gerencia coletivamente, a depender das exigências externas, o que fazer e como, quando, de quais formas e sob quais condições o trabalho será realizado. Também no dia-a-dia as pessoas planejam, replanejam e organizam os rumos do empreendimento (p.16).

A partir daí, é possível pensar que a questão da saúde do trabalhador em um empreendimento autogestionário também é pensada e decidida no cotidiano de trabalho, não apenas em assembleias. Essas ideias permitem reconhecer a existência de um conhecimento sobre o trabalho que se constrói e se acumula diariamente. As possibilidades do trabalhador de colocar em pauta e negociar a questão da saúde são, provavelmente, maiores que as de um trabalhador convencional, tendo em vista o controle que este tem em relação ao modo de produzir e organizar o próprio trabalho.

Novaes (2007) considera que nas Fábricas Recuperadas (FRs) existe o objetivo de facilitar ao máximo as vidas dos trabalhadores, tanto dentro quanto fora do ambiente de trabalho, o que o autor considera como uma humanização do espaço de trabalho pelos cooperados. O mesmo autor, tendo visitado algumas FRs, observou, ainda, o aumento da criatividade e o florescimento da inventividade no processo destes trabalhadores, mas, ao mesmo tempo, foi verificada a realização de trabalho alienante, repetitivo e desprovido de conteúdo.

Novaes (2007) crê que a alienação não se extingue por meio de um decreto, nem por uma modificação de propriedade jurídica, uma vez que entende, como Marx, que a tirania da circulação não é menos perversa do que a tirania da produção. Entende como contradição das cooperativas o movimento de governar a si mesmas com o mais extremo absolutismo e assinala que para uma real transformação seriam necessários o controle global das indústrias pelos associados e uma mudança qualitativa dentro do microcosmo das fábricas recuperadas. Desta forma, o autor aponta para contradições importantes na autogestão das FRs, pois, ao mesmo tempo que há um ideal autogestionário, na prática também pode-se observar que os trabalhadores se autoexploram e ainda contam com pouco conhecimento técnico, necessário à tomada de decisões do processo produtivo, o que acaba acarretando na formação de uma elite técnica (tecnocracia) dentro das FRs.

Sobre a saúde dos trabalhadores inseridos no mercado de trabalho, Lancman (2004) atribui o crescimento das DORT/LER a alguns fatores relacionados à organização do trabalho, tais como a separação entre planejamento e execução das atividades e as dificuldades ligadas à divisão e relação entre as pessoas, como: hierarquia rígida; relações de poder autoritárias; impossibilidade de o trabalhador contribuir com seu conhecimento e experiência para a transformação do trabalho; pressão da chefia; desconfiança e competição entre pares; obrigação de realizar hora extra; etc.

Dejours (2007) entende que "O processo de trabalho só funciona quando os trabalhadores beneficiam a organização do trabalho com a mobilização de suas inteligências individual e coletiva" (p. 56). Nesta perspectiva, é possível que, mesmo sem real autonomia para decidir as mudanças do processo produtivo, dando continuidade à lógica capitalista de produção, os cooperados possam, ainda assim, desconstruir as relações de trabalho apontadas por Lancman (2004). Desfazendo aos poucos as relações de hierarquia e autoritarismo, contribuindo com o conhecimento que tem para a 
transformação do trabalho, trabalhando de forma cooperativa, tendo autonomia de decisão quanto às horas a serem trabalhadas, se envolvendo mais com a tomada de decisões de uma forma geral, poderão transformar o trabalho em algo mais repleto de significados e, por tanto, menos alienante.

Lima e Gomez (2008) colocam que:

Diferentemente das empresas convencionais, no interior das unidades de produção associada, o controle das situações geradoras de agravos à saúde depende - em grande medida - da decisão dos próprios trabalhadores, em função das condições favoráveis - objetivas e subjetivas - presentes no andamento dos empreendimentos (p.3).

Sícoli (2007) trata das inúmeras repercussões negativas que tal atividade tem sobre a saúde dos trabalhadores e relata que o processo de tomada de consciência do nexo causal entre o adoecimento e o trabalho de triagem foi acontecendo no decorrer das entrevistas. Muitos dos cooperados, quando indagados sobre essa questão, não conseguiam fazer a conexão entre suas doenças e o trabalho, mas aos poucos, repetindo as entrevistas, a autora concluiu que suas perguntas provocaram reflexões nos trabalhadores sobre o seu dia a dia e o nexo foi sendo reconhecido. A importante relação entre a linguagem e a tomada de consciência vem do campo dos estudos da Ergonomia da Atividade Situada. Em 1988, François Daniellou e Catherine Teiger diziam: “Comment, d'ailleurs, se représenter les relations travail/santé, si l'on n'a pas l'occasion d'en parler? Tant qu'il n'y a pas de parole, la représentatioon elle-même n'est-elle pas limitée?” (1988, p. 79). ${ }^{3} \mathrm{Na}$ medida em que há maior possibilidade de falar do trabalho e de como a organização deste incide sobre o corpo do trabalhador, mais aumenta a percepção desta relação e das possibilidades de alteração existentes.

Um outro aspecto relevante da pesquisa realizada por Sícoli (2007) foi o apontamento de estratégias e micronegociações cotidianas utilizadas pelos membros para replanejar o trabalho da triagem a fim de beneficiar a todos. "Quem tá trabalhando mesmo é que vê o que é melhor e muda" (p. 249), diz uma das cooperadas, em relação ao processo de separação do copinho, que gerava um retrabalho para todos. Demonstra que o trabalho na autogestão permite recuperar e facilitar a compreensão do trabalhador das dificuldades daquele determinado trabalho e transformá-lo tendo em vista o melhor funcionamento e o bem-estar de todos. Apesar dessas constatações, a autora é cuidadosa ao afirmar que tal autonomia pode ser limitada em função dos outros níveis de relação da cooperativa, tais como as condições comerciais externas, que impõem regras que nem sempre beneficiam os trabalhadores, mas que precisam ser aceitas para que o trabalho renda, como, por exemplo, o tempo e o desgaste necessários para alcançar as metas que os compradores estabelecem, etc. Em suas considerações finais, coloca que não é possível afirmar que estes trabalhadores atingiram um grau de autonomia que lhes permita definir totalmente seu processo de trabalho e, portanto, suas condições de saúde.

Entretanto, Sícoli (2007) afirma também que, dentro do que é possível ser feito endogenamente, esses trabalhadores se encontram em uma verdadeira ambiguidade: a de lidar com a dimensão da necessidade econômica, que tende a priorizar aspectos de agilidade e intensidade no trabalho, e a dimensão social, que os leva a buscar a construção coletiva do processo organizativo no cotidiano, para que possam considerar a questão da saúde e da prevenção dos adoecimentos. A autora acredita que mesmo as pequenas decisões cotidianas em relação a saúde têm uma potência muito grande em relação à organização do trabalho e revelam uma resistência à racionalidade meramente econômica.

3 "Como, aliás, representar as relações trabalho/saúde se nós não temos oportunidade de falar? Se não há discurso, a representação ela mesma não é limitada?" (Em tradução livre do francês). 
Sendo assim, ainda que estes trabalhadores escolham um ritmo de trabalho que excede os limites do ritmo ideal, seguem tendo autonomia para decidir com relação a questões essenciais da dinâmica de trabalho: momento das pausas, turno de trabalho, negociação com colegas em relação às atividades desempenhadas, etc. Embora este trabalhador de EESs possa se sentir fisicamente cansado, a autonomia com relação às pequenas pausas, intervalo para refeição e duração dos turnos permite que o mesmo possa ter um ritmo de trabalho mais próximo do seu ideal, ao contrário da empresa capitalista, em que o ritmo de trabalho é igual para todos.

\section{Conclusão}

Ao consultar duas grandes bases de dados de periódicos brasileiros (Scielo e periódicos CAPES) utilizando como chaves de busca os termos "autogestão", "saúde do trabalhador" e "economia solidária", foram encontrados apenas dois artigos sobre a questão da saúde do trabalhador em empreendimentos autogeridos (Lima \& Minayo-Gomez, 2008; Azevedo \& Sousa, 2013). Somados à dissertação de Sícoli (2007), esses foram os únicos estudos encontrados sobre esta temática.

Buscamos aqui refletir sobre em que medida os processos autogestionários têm impacto sobre a saúde dos trabalhadores. $O$ fato de terem a autogestão como modo de funcionamento possibilita que escolhas organizacionais sejam feitas de modo a beneficiar a totalidade de trabalhadores. Por outro lado, a dificuldade de participação concreta dos trabalhadores de chão de fábrica (ainda que autogestionária) na tomada de decisões que concernem o processo produtivo e a necessidade de autoexploração dos trabalhadores apontam para a possibilidade de desgaste físico e psicológico no ambiente de trabalho. De que forma estariam, então, os trabalhadores dos EESs se relacionando com seu trabalho? Quais os impactos deste tipo de organização autogestionária para a saúde do trabalhador? Tentamos aqui apresentar algumas reflexões sobre estas questões, no entanto, fica evidente a necessidade de estudos que se proponham a analisar em campo as relações existentes entre a organização do processo produtivo e os impactos causados à saúde dos trabalhadores em EESs.

São necessários, ainda, estudos que indiquem o papel das instituições parceiras dos EESs (tais como as ITCPs, a ANTEAG, a UNISOL) junto dos mesmos na promoção à saúde do trabalhador.

\section{Bibliografia}

AEPS (2012). Anuário Estatístico da Previdência Social 2012. Seção IV-Acidentes de Trabalho. Disponível em: http:// www.previdencia.gov.br/estatisticas/aeps-2012-anuario-estatistico-da-previdencia-social-2012/aeps-2012secao-iv-acidentes-do-trabalho/aeps-2012-secao-iv-acidentes-do-trabalho-tabelas/

Andrade, M. C.; Burali, M. A. M.; Vida, A.; Fransozio, M. B. B. \& Santos, R. Z. (2013). Loucura e trabalho no encontro entre saúde mental e economia solidária. Psicologia: Ciência e Profissão, 33(1), 174-191.

Antunes, R. (2005). O Caracol e sua Concha: Ensaios sobre a nova morfologia do trabalho. São Paulo: Boitempo.

Antunes, R. (2010). Produção liofilizada e a precarização estrutural do trabalho. In: E. Lourenço et al. (orgs), O avesso do Trabalho II. São Paulo: Expressão Popular.

Azevedo, A. B. \& Sousa, S. (2013). Os dilemas da saúde e segurança do trabalho nas cooperativas. Revista da ABET, 12(1), 79-97.

Barros, D. D.; Lopes, R.E. \& Ghirardi, M. I. G. (2000). Terapia Ocupacional e Sociedade. Rev. de Ter. Ocup. da USP, $10,69-74$.

Barfknecht, K. S.; Merlo, A. R. C.; Nardi, H. C. (2006). Saúde mental e economia solidária: análise das relações de trabalho em uma cooperativa de confecção de Porto Alegre. Psicologia E̊ Sociedade, 18(2), 54-61. 
Bernardo, J. (2005). Autogestão da sociedade prepara-se na autogestão das lutas. Piá Piou! São Paulo.

Castel, R. (1998). As Metamorfoses da Questão Social, uma crônica do salário. São Paulo: Vozes.

Carreta, R. Y. C. D. (2005). Pessoas com deficiência organizando-se em cooperativas: uma alternativa de trabalho. Tese de Doutorado. Faculdade de Engenharia de Produção, UFSCar. São Carlos - SP.

Cruz, A. C. M. (2006) A diferença da igualdade: a dinâmica da economia solidaria em quatro cidades do MERCOSUL. 2006. Tese de Doutorado. Faculdade de Economia, Unicamp, Campinas - SP.

Dedecca, C. S. (1998). Emprego e qualificação no Brasil dos anos 90. In: M.A. Oliveira (org.), Economia e trabalho. Campinas, SP: UNICAMP, IE.

Dejours, C. (2007). Banalização da Injustiça Social. São Paulo: Fundação Getúlio Vargas.

Dejours, C. (1998) A Loucura do Trabalho - estudos de psicopatologia do trabalho (5 ed.). São Paulo: Cortez.

Faria, J. H. (2009) Gestão Participativa - Relações de Poder e de Trabalho nas organizações. São Paulo: Atlas.

Filizola, C. L. A.; Teixeira, I. M. C.; Milioni, D. B. \& Pavarini, S. F. I. (2011). Saúde mental e economia solidária: a família na inclusão pelo trabalho. Revista da Escola de Enfermagem da USP, 45(2), 418-425.

Georges, I. (2009) As novas configurações do trabalho: Precarização e economia solidária - comparações Brasil França. In: M. P. Leite \& A. M. C. Araújo (orgs). (2009) O Trabalho reconfigurado-ensaios sobre Brasil e México. São Paulo: Annablume.

Ghirardi, M. I. G. (2004). Trabalho e deficiência: as cooperativas como estratégia de inclusão social. Rev. de Ter. Ocup. da USP, 5(2), 49-54.

Lancman, S. (2004). Saúde, Trabalho e Terapia Ocupacional. São Paulo: Roca.

Lancilotti, S. S. P. (2003). Deficiência e trabalho: redimensionando o singular no contexto universal. Campinas: Autores Associados.

Lechat, N. M. P. (2002). Economia social, economia solidária, terceiro setor: do que se trata? Civitas, 2(1), 123-140. Porto Alegre Brasil.

Leite, M. P. (2003). Trabalho e sociedade em transformação. São Paulo: Fundação Perseu Abramo.

León-Cedeño, A. (1999) Guia Múltiplo da Autogestão: um passeio por diferentes fios de análise. Dissertação de Mestrado. Departamento de Psicologia Social, Pontifícia Universidade Católica de São Paulo, São Paulo.

Lima, J. C. (2007) Trabalho flexível e autogestão: estudo comparativo entre cooperativas de terceirização industrial. In: Ligações perigosas: trabalho flexível e trabalho associado. São Paulo: Annablume, pp. 127-169.

Lima, S. M. \& Minayo-Gomez, C. M. (2008). Construtores de casa e artífices de cidadania: modos cooperativos de trabalhar e viver. Trabalho, Educação e Saúde, 6(2), 321-340.

Luxemburgo, R. (2003). Reforma ou revolução? São Paulo: Expressão Popular.

MNCR, Movimento Nacional dos Catadores de Materiais Recicláveis. (2009) A crise financeira e os catadores de materiais recicláveis. Mercado de trabalho conjuntura e análise, Ipea, 41, Brasília: MTE, p. 55-58.

Nicacio, F.; Mangia, E. F. \& Ghirardi, M. I. G. (2005). Projetos de Inclusão no Trabalho e Emancipação de pessoas em situação de desvantagem: uma discussão de perspectivas. Rev. de Ter. Ocup. da USP, 16, 62-66.

Novaes, H. T. (2007). O fetiche da tecnologia: a experiência das fábricas recuperadas. São Paulo: Expressão Popular. OIT (2007). Locais de trabalho seguros e saudáveis: tornar o trabalho digno uma realidade. Relatório do BIT para o Dia Mundial da Segurança e Saúde no Trabalho, Genebra. Disponível em:: www.ilo.org/public/portugue/region/ eurpro/lisbon/pdf/relatseg_07.pdf $\square$

Pochmann, M. (2002). O Emprego na Globalização: a nova divisão internacional do trabalho e os caminhos que o Brasil escolheu. São Paulo: Boitempo.

Quijano, A. (2005). Sistemas alternativos de produção? In: B. S. Santos (org.), Produzir para viver. Rio de Janeiro: Civilização Brasileira.

Santos, B. S. (2002). Produzir para viver. Os caminhos da produção não capitalista. São Paulo: Ed. Civilização Brasileira.

Santos, M. (2010). O lugar e o cotidiano. In: B. S. Santos \& M. P. Menezes (Orgs.), Epistemologias do Sul. São Paulo: Cortez, pp. 584-602.

Sato, L. \& Esteves, E. G. (2002). Autogestão: possibilidades e ambigüidades de um processo organizativo peculiar. São Paulo, SP: ADS/CUT 
Sato, L. (1993). A representação social do trabalho penoso. In: M. J. Spink (org). O conhecimento no cotidiano: as representações sociais na perspectiva da psicologia social. São Paulo: Ed. Brasiliense.

Sato, L. (1996). As implicações do conhecimento prático para a vigilância em saúde do trabalhador. Cadernos Saúde Pública, 4, 489-495.

Sato, L. et al. (2006). Psicologia e saúde do trabalhador: práticas e investigações na Saúde Pública de São Paulo. Estudos de Psicologia, 11 (3), 281-228.

Scopinho, R. (2007). Sobre a cooperação e cooperativas em assentamentos rurais. Psicologia e Sociedade, 19, $\mathrm{n}^{\circ}$ edição especial 1, 85-94.

Sicoli, J. L. (2007). Potencialidades e limites da autogestão ao nível da organização do trabalho e suas repercussões à saúde dos trabalhadores: estudo etnográfico da Coopermare - Cooperativa de Reciclagem de Matéria-Prima de Embu. Dissertação de Mestrado. Universidade de São Paulo. São Paulo.

Singer, P. (2002). Introdução à Economia Solidária. São Paulo: Editora Fundação Perseu Abramo.

Spink, P. (1996). A organização como fenômeno psicossocial: notas para uma redefinição da psicologia organizacional. Revista Psicologia e Sociedade, 8(1), jan/jun.

Teiger, C.; Daniellou, F (1988) Organisation du travail, santé. In: C. Dejours (dir.), Plaisir et souffrance dans le travail. Paris: Ed. Psy. T.A. tomo 1, pp. 77-88.

\section{Endereço para correspondência} tatidimov@gmail.com, 